\title{
Positive end expiratory pressure in acute and chronic respiratory distress
}

\author{
A Greenough, V Chan, M F Hird
}

\begin{abstract}
The optimum level of positive end expiratory pressure (PEEP) was determined in 16 infants with respiratory distress syndrome (median gestational age 29 weeks, median postnatal age 1 day) and in 16 infants with chronic respiratory distress (median gestational age 25 weeks, median postnatal age 15 days). All infants were studied at a PEEP sequence of 3 , $0,3,6$, and $3 \mathrm{~cm} \mathrm{H}_{2} \mathrm{O}$, all other ventilator parameters being kept constant. Each PEEP level was maintained for 20 minutes and at the end of each period arterial blood gas was checked. During acute respiratory distress syndrome there were no significant changes in oxygenation but arterial carbon dioxide tension $\left(\mathrm{PaCO}_{2}\right)$ significantly decreased from a mean of $4.93 \mathrm{kPa}$ at $3 \mathrm{~cm} \mathrm{H}_{2} \mathrm{O}$ to $4.40 \mathrm{kPa}$ at $0 \mathrm{~cm} \mathrm{H}_{2} \mathrm{O}$ and increased to a mean of $5.87 \mathrm{kPa}$ at $6 \mathrm{~cm} \mathrm{H}_{2} \mathrm{O}$. In the infants with chronic respiratory distress, oxygenation fell from a mean of $8.66 \mathrm{kPa}$ at $3 \mathrm{~cm} \mathrm{H_{2 }} \mathrm{O}$ to $6.40 \mathrm{kPa}$ at 0 $\mathrm{cm} \mathrm{H}_{2} \mathrm{O}$ and improved at $6 \mathrm{~cm} \mathrm{H}_{2} \mathrm{O}$ to a mean of $10.50 \mathrm{kPa}$. There were no significant changes in $\mathrm{PaCO}_{2}$. We conclude that addition of PEEP, up to $6 \mathrm{~cm} \mathrm{H}_{2} \mathrm{O}$, may be useful even after the first week of life. High levels of PEEP, however, have previously been reported, in certain infants, to result in circulatory disturbance. It is therefore important to assess the use of $6 \mathrm{~cm} \mathrm{H}_{2} O$ PEEP in a controlled study of longer term clinical outcome.
\end{abstract}

During acute respiratory distress syndrome addition of positive end expiratory pressure (PEEP) during mechanical ventilation is useful. ${ }^{1}$ Addition of PEEP increases mean airway pressure improving oxygenation, ${ }^{2} 3$ and it also results in surfactant conservation. ${ }^{4}$ In severe respiratory distress syndrome levels of PEEP of up to $10 \mathrm{~cm} \mathrm{H}_{2} \mathrm{O}$ have been recommended. ${ }^{5}$ Such studies, however, were performed on infants with severe respiratory distress synrome. ${ }^{1-35}$

Many of the present population of preterm infants do not suffer from severe respiratory failure. It has been suggested that among this group of infants even relatively low levels of PEEP may cause alveolar overdistension, with reduced compliance and carbon dioxide retention. ${ }^{6}$ Those results, however, may be explained by the inclusion of relatively mature infants (mean gestational age 32 weeks). Investigation of very immature infants, whose respiratory distress would be expected to be more severe, may still demonstrate that addition of PEEP during mechanical ventilation may be beneficial. It is also difficult to predict the optimum PEEP levels in infants remaining ventilated beyond the first week of life as at this age airways resistance is high, ${ }^{7}$ yet surfactant abnormalities may coexist. ${ }^{8}$ The aim of this study was to determine the optimum level of PEEP during mechanical ventilation of very preterm infants with acute respiratory distress and to see if this differed for infants ventilated beyond the first week of life.

\section{Methods}

Consecutive infants were recruited into the study who had been ventilated either for less than four days (acute respiratory distress) or at least 14 days (chronic respiratory distress). Infants with congenital or nosocomial pneumonia were excluded from the study.

Infants were all studied at the same sequence of PEEP levels, 3, 0, 3, 6, and $3 \mathrm{~cm} \mathrm{H}_{2} \mathrm{O}(3 \mathrm{~cm}$ $\mathrm{H}_{2} \mathrm{O}$ being the baseline level), each level being maintained for 20 minutes. The three levels of PEEP were chosen as they all had previously been used on our unit during routine clinical management of infants with respiratory distress. Peak inflating pressure, inspiratory:expiratory ratio, ventilator rate, and inspired oxygen concentration were kept constant at each PEEP level.

Throughout the PEEP sequence infants were continuously monitored by an intra-arterial Searle electrode or a transcutaneous oxygen electrode. If this monitoring demonstrated the arterial oxygen tension $\left(\mathrm{PaO}_{2}\right)$ to fall below $5 \cdot 33$ $\mathrm{kPa}$ the infant was immediately returned to the baseline PEEP level. The inspired oxygen concentration was increased after checking the arterial blood gas, and the study then abandoned.

At the start of the study and at the end of each 20 minute period, arterial blood gases were checked from the indwelling catheter sited for clinical purposes. $\mathrm{PaO}_{2}$ and arterial carbondioxide tension $\left(\mathrm{PaCO}_{2}\right)$ values at 0 and $6 \mathrm{~cm}$ $\mathrm{H}_{2} \mathrm{O}$ were then compared with the mean value obtained at the three periods at the baseline of 3 $\mathrm{cm} \mathrm{H}_{2} \mathrm{O}$ of PEEP.

\section{TRIAL SIZE}

Recruitment of 16 infants into each group gave us the possibility of detecting a change of $2 \cdot 13$ $\mathrm{kPa}$ in oxygenation and $1.07 \mathrm{kPa}$ in $\mathrm{PaCO}_{2}$ between PEEP levels in the infants with acute respiratory distress with $80 \%$ power at the $5 \%$ level, and a change of $2.00 \mathrm{kPa}$ in oxygenation and $1.33 \mathrm{kPa}$ in $\mathrm{PaCO}_{2}$ in the infants with 
chronic respiratory distress with $85 \%$ power at the $5 \%$ level.

STATISTICAL ANALYSIS

To assess if differences at different PEEP levels were significant a Student's $t$ test was used. The confidence intervals were calculated with the appropriate $p$ value from the standard error of the difference between the different PEEP levels. To assess if differences between groups were significant a Wilcoxon rank sum test or Fisher's exact test was used.

\section{Patients}

Sixteen infants were studied in the first four days of life, all of whom were ventilated for respiratory distress syndrome. Their median gestational age was 29 weeks (range 23-33), postnatal age was 1 day $(0.5-4)$, and birth weight $1054 \mathrm{~g}(510-2110)$. The median inspired oxygen concentration of these patients was 33\% (range 21-95) and their peak inspiratory pressure was $16 \mathrm{~cm} \mathrm{H}_{2} \mathrm{O}$ (range 14-27).

Another group of 16 infants were studied: they had been ventilated initially for respiratory distress syndrome but then remained fully ventilator dependent (rates $\geqslant 30$ breaths/minute) beyond 1 week of age. Their median gestational age was 25 weeks (range 24-29), birth weight $806 \mathrm{~g}$ (range 600-1140), and postnatal age 15 days (range 12:5-31). Only two infants were older than 3 weeks of age, but both were recruited at the beginning of the study. The median inspired oxygen concentration of the 16 patients was $40 \%$ (range 28-80) and peak pressure was $17 \mathrm{~cm} \mathrm{H}_{2} \mathrm{O}$ (range 14-24). At the time of entry into the study five infants were receiving dexamethasone to facilitate weaning from mechanical ventilation. When infants were older than 2 weeks of age they were entered into the study on the first occasion a chest radiograph was taken for clinical purposes. The chest radiograph was used to determine the nature of the infant's chronic respiratory distress. The radiographs of nine infants demonstrated areas of collapse and consolidation. One infant had resolving pulmonary interstitial emphysema and two others had evolving bronchopulmonary dysplasia with overinflated lungs. The remaining four infants all had evidence of heart failure and were the only four infants who had a patent ductus arteriosus at the time of study.

Ethical permission for this study was granted by the King's College Hospital ethical committee.

\section{Results}

One infant with chronic respiratory distress did not complete the 20 minute period at $0 \mathrm{~cm} \mathrm{H}_{2} \mathrm{O}$. After 10 minutes the continuous monitoring indicated the $\mathrm{PaO}_{2}$ had fallen below $5.33 \mathrm{kPa}$, an arterial blood gas reading was taken which indicated the $\mathrm{PaO}_{2}$ was in fact $3.20 \mathrm{kPa}$, so the infant was immediately returned to $3 \mathrm{~cm} \mathrm{H}_{2} \mathrm{O}$ PEEP. No other infant showed such an appreciable deterioration in blood gases at any PEEP level.

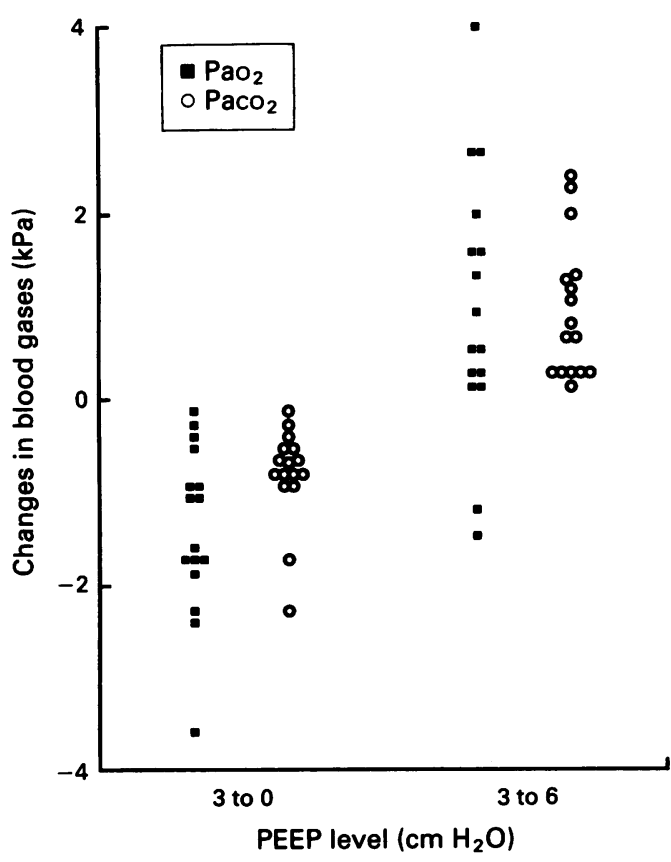

Figure 1 Changes in $\mathrm{PaO}_{2}$ and $\mathrm{PaCO}_{2}$ at different PEEP levels in acute respiratory distress syndrome. Individual data are displayed as the change in $\mathrm{PaO}_{2}$ or $\mathrm{PaCO}_{2}$ from the baseline.

Respiratory distress in the two groups of infants. Results are mean ( $S E$ of difference from baseline) in $\mathrm{kPa}$

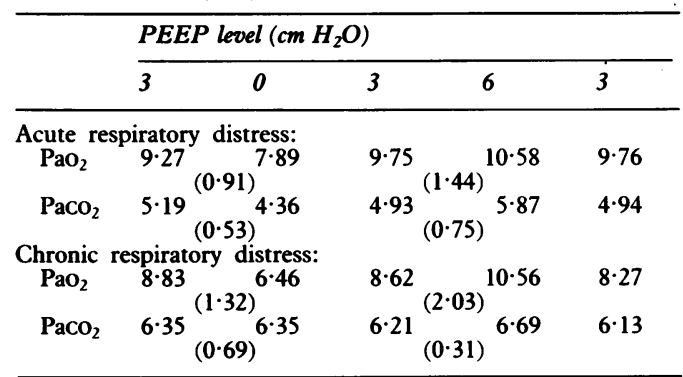

ACUTE RESPIRATORY DISTRESS

In the 16 infants overall there was no significant change in oxygenation at either 0 or $6 \mathrm{~cm} \mathrm{H}_{2} \mathrm{O}$ compared with baseline (fig 1, table). For $\mathrm{PaO}_{2}$, the $95 \%$ confidence intervals of the difference of the means of 3 and $0 \mathrm{~cm} \mathrm{H}_{2} \mathrm{O}$ PEEP were $0 \cdot 10$ to $2 \cdot 81 \mathrm{kPa}$ and of 3 and $6 \mathrm{~cm} \mathrm{H} \mathrm{H}_{2} \mathrm{O}$ PEEP were -0.44 to $2.27 \mathrm{kPa}$. $\mathrm{PaCO}_{2}$ was significantly lower at $0 \mathrm{~cm} \mathrm{H} \mathrm{H}_{2} \mathrm{O}(\mathrm{p}<0.05)$ and significantly higher at $6 \mathrm{~cm} \mathrm{H} \mathrm{H}_{2} \mathrm{O}(\mathrm{p}<0.01)$ compared with baseline. For $\mathrm{PaCO}_{2}$, the $95 \%$ confidence intervals of the difference of the means of 3 and $0 \mathrm{~cm} \mathrm{H} \mathrm{H}_{2} \mathrm{O}$ PEEP were 0.12 to $1.56 \mathrm{kPa}$ and of 3 and $6 \mathrm{~cm} \mathrm{H} \mathrm{H}_{2} \mathrm{O}$ PEEP were $0 \cdot 10$ to $2 \cdot 00 \mathrm{kPa}$.

Fourteen of the 16 infants showed similar trends in blood gases with changes in the PEEP levels; that is, an increase in both $\mathrm{PaO}_{2}$ and $\mathrm{PaCO}_{2}$ at $6 \mathrm{~cm} \mathrm{H}_{2} \mathrm{O}$ and a decrease in $\mathrm{PaO}_{2}$ and $\mathrm{PaCO}_{2}$ at $\mathbf{0 ~} \mathrm{cm} \mathrm{H}_{2} \mathrm{O}$, but the changes were small. Two infants, however, although showing a similar trend in $\mathrm{PaCO}_{2}$ to the rest of the study group had a deterioration in $\mathrm{PaO}_{2}$ at both $\mathrm{O}$ and $6 \mathrm{~cm} \mathrm{H}_{2} \mathrm{O}$. These two infants did not differ significantly in either postnatal age ur baseline blood gas values from the rest of the group. 


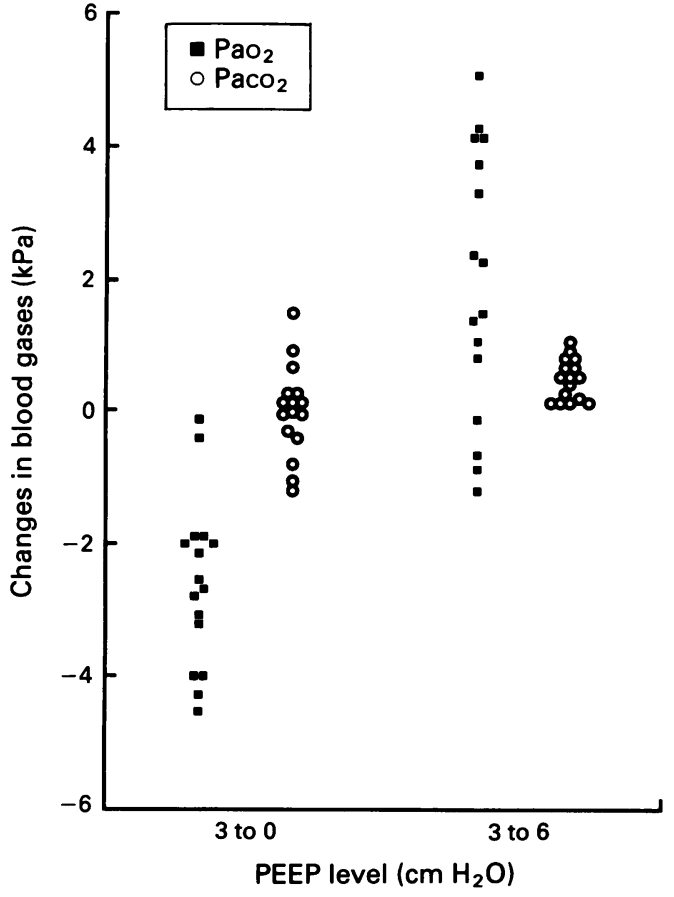

Figure 2 Changes in $\mathrm{PaO}_{2}$ and $\mathrm{PaCO}_{2}$ at different PEEP levels in chronic respiratory distress syndrome. Individual data are displayed as the change in $\mathrm{PaO}_{2}$ or $\mathrm{PaCO}_{2}$ from the baseline.

\section{CHRONIC RESPIRATORY DISTRESS}

In the group overall the trends in changes in $\mathrm{PaO}_{2}$ were similar to those seen in the infants with acute respiratory distress, but they were much larger (fig 2) and were significant at both $0 \mathrm{~cm} \mathrm{H} \mathrm{H}_{2} \mathrm{O}(\mathrm{p}<0.01)$ and $6 \mathrm{~cm} \mathrm{H}_{2} \mathrm{O}(\mathrm{p}<0.01)$. For $\mathrm{PaO}_{2}$, the $95 \%$ confidence intervals of the difference of the means of 0 and $3 \mathrm{~cm} \mathrm{H}_{2} \mathrm{O}$ were 1.25 to $3.50 \mathrm{kPa}$ and of 3 and $6 \mathrm{~cm} \mathrm{H}_{2} \mathrm{O}$ were 0.31 to $3.57 \mathrm{kPa}$. There was, however, no significant change in $\mathrm{PaCO}_{2}$ with changes in PEEP (table). For $\mathrm{PaCO}_{2}$ the $95 \%$ confidence intervals for the difference in the means of 0 and $3 \mathrm{~cm} \mathrm{H}_{2} \mathrm{O}$ PEEP were -0.88 to $0.89 \mathrm{kPa}$ and of 3 and $6 \mathrm{~cm} \mathrm{H}_{2} \mathrm{O}$ were -0.39 to $1.48 \mathrm{kPa}$.

Twelve of the 16 infants showed similar trends in blood gases with changes in PEEP levels; that is, an increase in $\mathrm{PaO}_{2}$ and $\mathrm{PaCO}_{2}$ at 6 $\mathrm{cm} \mathrm{H}_{2} \mathrm{O}$ and decrease in $\mathrm{PaO}_{2}$ at $0 \mathrm{~cm} \mathrm{H} \mathrm{H}_{2} \mathrm{O}$. Four infants had similar changes in $\mathrm{PaCO}_{2}$ values to the rest of the group and impairment of oxygenation at $0 \mathrm{~cm} \mathrm{H}_{2} \mathrm{O}$, but showed a reduction in $\mathrm{PaO}_{2}$ at $6 \mathrm{~cm} \mathrm{H} \mathrm{H}_{2} \mathrm{O}$ compared with baseline. These four infants did not differ significantly from the rest of the group in either postnatal age or baseline blood gases, but did have a different chest radiograph appearance to the other 12 infants. These four infants were the only ones whose chest radiograph appearance was compatible with heart failure and had a patent ductus arteriosus at the time of study. There was no significant difference in the oxygen requirements or peak inspiratory pressure in the four infants and the remainder of the group.

\section{Discussion}

We felt it important to perform exactly the same protocol in the two groups as, by allowing direct comparison, this facilitated determination of differences in the effect of PEEP with increasing postnatal age. Infants were left at each PEEP level for 20 minutes and as we assessed the effect by measuring arterial blood gases rather than transcutaneous values, ${ }^{6}$ we felt this was sufficient time for stabilisation at the new PEEP level. To minimise the effect of a trend with increasing time the infants were always returned to the baseline $3 \mathrm{~cm} \mathrm{H}_{2} \mathrm{O}$ immediately after the period at the experimental PEEP level.

These results demonstrate that increasing postnatal age did not affect the response to increasing PEEP levels as determined by trends in changes in oxygenation. In the infants with chronic respiratory distress oxygenation was significantly improved at $6 \mathrm{~cm} \mathrm{H}_{2} \mathrm{O}$ and impaired at $0 \mathrm{~cm} \mathrm{H}_{2} \mathrm{O}$. Similar trends were seen in the infants with acute respiratory distress but the changes were very small. Similar differences in response have been demonstrated in other respiratory diagnoses. Field $e t$ al noted a much greater improvement in oxygenation among infants with apnoea of prematurity than in those with respiratory distress syndrome, the former group having the lower compliance. ${ }^{6}$ Our infants with chronic respiratory distress were ventilated at similar pressures to those with acute respiratory distress but had higher $\mathrm{PaCO}_{2}$, suggesting that they did have lower lung compliance. This seems likely as their median gestational age was 25 weeks compared with 29 weeks of the acute respiratory distress group.

Four of the 16 infants with chronic respiratory distress did not show an improvement in oxygenation at $6 \mathrm{~cm} \mathrm{H}_{2} \mathrm{O}$. Interestingly, these four infants were the only ones who had a chest radiograph appearance compatible with heart failure and had a patent ductus arteriosus at the time of study. Our results, therefore, seem surprising as the presence of a patent ductus arteriosus associated with heart failure might reduce lung compliance and thus a higher level of PEEP would be predicted to be more appropriate. The similar peak inspiratory pressures and inspired oxygen concentration in these infants compared with the rest of the group, however, suggest similar degrees of lung function impairment. Addition of PEEP in this group, however, was still clearly useful, as oxygenation deteriorated when the PEEP level was changed from 3 to $0 \mathrm{~cm} \mathrm{H}_{2} \mathrm{O}$. Our results may indicate that the optimum level of PEEP in such infants is $3 \mathrm{~cm} \mathrm{H}_{2} \mathrm{O}$, but as only four infants were involved we need to assess if this response is consistent in greater numbers of infants.

Increasing PEEP while maintaining peak inspiratory pressure constant is likely to reduce both delivered volume and minute volume. This reduction in delivered volume may partially explain the significant increase in $\mathrm{PaCO}_{2}$ values at higher PEEP levels seen among our infants with acute respiratory distress. The effect of carbon dioxide retention was greater in this study than that of Field et al and the likely explanation is that we used higher PEEP levels. ${ }^{6}$ No significant effect on carbon dioxide values was seen in the infants with chronic respiratory distress. There was, however, an upward trend 
in $\mathrm{PaCO}_{2}$ values with increased PEEP and our results may have failed to reach significance due to a small sample size. It is also possible that a further mechanism might operate to alter $\mathrm{PaCO}_{2}$ values with changing levels of PEEP. Richardson et al found that, although changes in $\mathrm{PaO}_{2}$ did not correlate well with change in functional residual capacity, in those infants in whom an impairment of oxygenation was associated with an increase in functional residual capacity there was always an accompanying increase in $\mathrm{PaCO}_{2}-$ indicating alveolar overdistension and decreased alveolar ventilation. ${ }^{5}$ Thus our results may imply that the infants with acute respiratory distress had more compliant lungs than those with chronic respiratory distress and were thus more susceptible to increasing levels of PEEP causing alveolar overdistension and carbon dioxide retention.

It might have been expected that increasing PEEP levels in infants with chronic respiratory distress would also cause alveolar overdistension and carbon dioxide retention. This sequela is most likely to occur in infants with hyperinflated lungs which contain cystic areas typical of Northway type IV bronchopulmonary dysplasia. Infants with this chest radiograph appearance, however, represent the minority of infants ventilated beyond the first week of life ${ }^{9}$ and indeed were only two of our 16 subjects consecutively recruited into the study. The majority of infants who require respiratory support after the first week of life suffer from type I chronic lung disease ${ }^{10}$ and are represented by our group of nine infants whose chest radiograph showed evidence of areas of collapse. Such infants have underexpanded areas of lung which could be recruited by increasing PEEP without causing overdistension and carbon dioxide retention.

These results demonstrate that increasing the PEEP level continues to have an advantageous effect even after the first week of life, and that in chronic respiratory distress PEEP levels as high as $6 \mathrm{~cm} \mathrm{H}_{2} \mathrm{O}$ can improve oxygenation without significant carbon dioxide retention; this finding is important. The strategy of increasing PEEP levels would allow maintenance of arterial blood gases at lower peak pressures during subsequent ventilation which might reduce further lung damage. It must be stressed, however, that high levels of PEEP can be associated with circulatory disturbance. In surfactant depleted rabbit's lungs, although adequate arterial oxygenation can be maintained with PEEP at $10 \mathrm{~cm} \mathrm{H}_{2} \mathrm{O}$, the associated circulatory impairment, as evidenced by reduced arterial pressure and aortic blood flow, results in inadequate oxygen delivery. ${ }^{11}$ In another animal model ${ }^{12}$ increasing PEEP from 5 to 15 $\mathrm{cm} \mathrm{H}_{2} \mathrm{O}$ resulted in a reduction in left ventricular stroke volume, which was due to impaired left ventricular filling rather than a concomitant depression of myocardial contractility. In the present study no such adverse effects were experienced but the maximum PEEP level used was lower than in the other studies. These data, however, stress the importance of proceeding to assess the use of $6 \mathrm{~cm} \mathrm{H}_{2} \mathrm{O}$ in infants with chronic respiratory distress in controlled studies of longer term clinical outcome.

Dr Vivien Chan and Dr Michael F Hird are supported by Children Nationwide Medical Research Fund. We thank Ms Sue Williams for secretarial assistance.

1 Stewart AR, Finer NN, Delroy KL. Effect of alterations of inspiratory and expiratory pressures and inspiratory/ expiratory ratios on mean airways pressure, blood gases and intracranial pressure. Pediatrics 1981;67:474-81.

2 Boros SJ. Variations in inspiratory:expiratory ratio and airway pressure wave form during mechanical ventilation: the significance of mean airway pressure. $\mathcal{F}$ Pediatr 1979; 94:114-7.

3 Boros SJ, Campbell K. A comparison of the effects of high frequency-low tidal volume and low frequency-high tidal volume mechanical ventilation. $\mathcal{f}$ Pediatr 1980;97:108-12. yszogrodski I, Kyer-Aboagye K, Taeusch HW. Surfactant inactivation by hyperventilation, conservation by

5 Richardson CP, Jung AL. Effects of continuous positive airway pressure on pulmonary function and blood gases of
arionas airway pressure on pulmonary function and blood gases of
infants with respiratory distress syndrome. Pediatr Res 1978;12:771-4.

6 Field D, Milner AD, Hopkins IE. Effects of positive end expiratory pressure during ventilation of the preterm infant. Arch Dis Child 1985;60:843-7.

7 Wilkie RA, Bryan MH. Effect of bronchodilator on airway resistance in ventilator dependent neonates with chronic lung disease. $\mathcal{F}$ Pediatr 1987;111:278-82.

8 Obladen $M$. Alterations in surfactant composition. In: Merritt A, Northway WH, Boynton BR, eds. Bronchopulmonary dysplasia. Boston: Blackwell Scientific Publications, 1988:131-41.

9 Greenough A. Bronchopulmonary dysplasia. Arch Dis Child 1990;65:1082-8.

10 Hyde I, English RE, Williams JD. The changing pattern of chronic lung disease of prematurity. Arch Dis Child 1989;64:448-51.

11 Chakrabarti MK, Holdcroft A, Sapsed-Byne S, Whitwam JG. Circulatory depression with high PEEP in the JG. Circulatory depression with high PEEP in the
surfactant-deficient rabbit. Br $\mathcal{f}$ Anaesth 1989;63:732-5.

12 Johnston WE, Santamore WP, Case LD, Little WC. Mechanism of reduced cardiac output during positive end expiratory pressure
$1989 ; 140: 1257-64$. 